Vol. 19(2010): 284-293.

\title{
Microsatellite, blood group and transferrin protein diversity of Estonian dairy cattle breeds
}

\author{
Sirje Värv ${ }^{1 *}$, Juha Kantanen ${ }^{2}$ and Haldja Viinalass ${ }^{1}$ \\ ${ }^{1}$ Institute of Veterinary Medicine and Animal Sciences, Estonian University of Life Sciences, Kreutzwaldi 1, \\ EE-51014 Tartu, Estonia, *e-mail: sirje.varv@emu.ee \\ ${ }^{2}$ Biotechnology and Food Research, MTT Agrifood Research Finland, FI-31600 Jokioinen, Finland
}

\begin{abstract}
This study investigates genetic diversity within and among three Estonian dairy cattle breeds (Estonian Native, Estonian Red and Estonian Holstein). A total of 36 markers (25 microsatellites, 10 blood group systems and transferrin protein) were investigated and the within-breed diversity was quantified by expected heterozygosity, number of private alleles and mean allelic richness. The population structure was studied by computing the inbreeding coefficients, breed differentiation and relationships were investigated with random drift-based measures and a factorial correspondence analysis. In addition, a neighbour-joining tree was drawn summarising allele sharing distances for 195 individuals of the Estonian breeds, Western Finncattle, and Danish Jersey. The Estonian breeds displayed generally similar levels of within-population diversity. Depending on the set of markers used 6.2 or $4.3 \%$ of the total genetic variation can be explained by differences among the breeds. Construction of the tree for individuals revealed a distinctive pattern of grouping for Estonian Holstein, Estonian Red and Danish Jersey, but Estonian Native and Western Finncattle appeared on the same branches. This indicates that the gene pool of Estonian Native largely overlaps with that of Western Finncattle. However, our genetic marker analysis shows that the three Estonian breeds are genetically differentiated, suggesting that the current gene pool of Estonian dairy cattle is diverse.
\end{abstract}

Key-words: blood group, cattle, genetic diversity, microsatellite, transferrin

\section{Introduction}

Population genetic structures of domestic cattle breeds are greatly influenced by human activities. Different ancestral and demographic histories can generate dissimilar patterns of genetic variation within and among breeds, which can be effectively measured using genetic marker analysis (IbeaghaAwemu et al. 2004; Li et al. 2007; Mao et al. 2007). Three dairy cattle breeds of different origins and 
Vol. 19(2010): 284-293.

census sizes are currently raised in Estonia. Estonian Native Cattle are of old Estonian origin and were officially recognised in 1914 when the herd book for the breed was established. The present population (500 breeding females) has been influenced by the use of Western Finncattle A.I. bulls during the $20^{\text {th }}$ Century. Since 1995 a conservation programme for Estonian Native Cattle has been implemented, including the collection of embryos for an ex situ gene bank for the breed. The Estonian Holstein Breed, which comprises $75 \%$ of the dairy cattle population (98 500 dairy cows in 2009) in Estonia, and the Estonian Red (21 000 breeding females) are the main dairy cattle breeds in Estonia. Their herd books were established in 1885. The Estonian Holstein originally descended from Dutch Friesian cattle, with a marked introduction of international Holstein semen since the late 1970s. The Estonian Red Cattle contain genes sourced from a broad Angeln and Danish Red base. Estonian breeders, being incorporated with the European Red Dairy Breed Association, are using genetic material focal to all European red cattle breeds.

Tapio et al. (2006) analysed genetic diversity using microsatellite markers in 35 North European cattle breeds, including Estonian Native and Estonian Red. Their study showed that the Estonian Native Cattle share common ancestries with the Finnish and Scandinavian native breeds, while the Estonian Red belongs to the group of Baltic red breeds. In addition, Tapio et al. (2006) demonstrated that the Estonian Native Cattle are of a high value in the conservation of cattle genetic resources when the prioritisation of cattle breeds is based simultaneously on within- and between-breed components of genetic diversity. However, that study did not include the Estonian Holstein Cattle.

Here we study for the first time the molecular genetic diversity of this breed and increase the number of microsatellites used to analyse all Estonian dairy cattle breeds. In addition, we analyse erythrocyte antigen (EA) systems (or blood groups) and blood protein in the Estonian dairy breeds. Our attempt is to apply genotypes in the blood group systems to make more diverse use of them by typing also the parents and/or offspring of the studied individuals. In studies where genetic data have come from typings of one generation, simplification and modification of the mode of inheritance are typically needed (Blott et al. 1998; Kantanen et al. 1999). In the blood-group systems EAA, EAB, EAC and EAS, the antigenic factors form complexes that are inherited as haplotypic blocks. Also a recessive allele segregates in these complex blood groups and in bi-allelic systems EAJ, EAL, EAM, and EAZ.

Previously, Arranz et al. (1996), MoazamiGoudarzi et al. (1997) and Kantanen et al. (2000) compared microsatellites and biochemical markers in cattle, and e.g. Barker et al. (1997), Luís et al. (2007) and Tapio et al. (2003) studied polymorphisms in these two types of markers in water buffaloes, horses and sheep, respectively. These two marker types typically give congruent results for population divergence (Arranz et al. 1996; Luís et al. 2007). The aim of the present study is to analyse genetic diversity and differentiation of the three Estonian dairy cattle breeds by comparing genotypic and allelic data of microsatellites and blood groups - protein markers. In addition, we investigate the divergence of Estonian Native Breed from the breeds (Western Finncattle, Jersey and the two other Estonian breeds) that have had genetic influence on the gene pool of the breed in order to identify animals with the most pure Estonian origins.

\section{Materials and Methods}

\section{Sampling}

We collected blood samples from 40 Estonian Native, 40 Estonian Red and 34 Estonian Holstein cattle. The sampled individuals originated from 14, 7 and 17 farms located in distinct regions of Estonia. Animals were pre-selected using pedigree data kept by the Estonian Animal Recording Center. For each animal three generations were considered to avoid sampling closely related animals. Sires of Estonian Native and Estonian Red animals were of Estonian origin and therefore our samples represent characteristic present-day types of these breeds. For Estonian Holstein, in turn, it was difficult 


\section{AGRICULTURAL AND FOOD SCIENCE}

Värv, S. et al. Diversity among the Estonian dairy breeds

to find animals sired by the old type of Estonian Black-and-White Cattle and the animals included in the present study were descended from modern international Holstein bulls.

\section{DNA extraction and marker analysis}

For this study, DNA from the blood samples of Estonian Holstein Cattle was extracted using a Genomic DNA Purification Kit (MBI Fermentas, Lithuania). For the Estonian Native and Estonian Red Cattle, DNA samples for the typing of microsatellites were available from a previous study (Tapio et al. 2006).

The individuals were analysed for 25 microsatellites, 10 blood group loci, and the transferrin protein locus. Data for the following 20 microsatellites were available for the Estonian Native and Estonian Red breeds (Tapio et al. 2006): BM1818, BM1824, BM2113, CSSM66, ETH003, ETH010, ETH152, ETH225, HEL005, HEL01, HELO9, HEL13, ILSTS005, ILSTSO06, INRA005, INRA023, INRA032, INRA035, INRA037, and INRA063. In addition to these microsatellites, we typed a further five microsatellites: TGLA053, TGLA122, TGLA126, TGLA227, and SPS115. Moreover, these additional markers are recommended by the International Society for Animal Genetics (ISAG) and the Food and Agriculture Organization of the United Nations (FAO) for cattle genetic diversity studies. The Estonian Holstein Cattle, which were not included in the previous microsatellite study by Tapio et al. (2006), were typed for all 25 microsatellites. We carried out the PCR reactions to amplify microsatellite loci in a $25 \mu \mathrm{l}$ reaction mixture including $7.5-20$ pmol of each primer, $200 \mu \mathrm{M}$ of each dNTP, DynaZyme ${ }^{\mathrm{TM}}$ - buffer (Finnzymes, Finland), 50 ng of DNA template, and 1 U of DynaZyme ${ }^{\mathrm{TM}}$ II DNA polymerase (Finnzymes). Annealing temperatures in the PCR for different microsatellites ranged from 55 to $58^{\circ} \mathrm{C}$ and the amplified products were separated on a MegaBACE ${ }^{\mathrm{TM}} 500$ DNA Sequencer (Amersham Biosciences, UK). The consistency in size of microsatellite alleles was assured by comparison with control samples available from the study of Tapio et al. (2006).
A total of 60 erythrocyte antigenic (EA) factors for the 10 systems were typed. These were: $A_{1}$, and $A_{2}$ in the blood group system $A(E A A) ; B_{1}, B_{2}, G_{1}$, $\mathrm{G}_{2}, \mathrm{G}_{3}, \mathrm{I}_{1}, \mathrm{I}_{2}, \mathrm{~K}, \mathrm{O}_{1}, \mathrm{O}_{2}, \mathrm{P}_{1}, \mathrm{P}_{2}, \mathrm{Q}, \mathrm{T}_{1}, \mathrm{~T}_{2}, \mathrm{Y}_{2}, \mathrm{~A}^{\prime}$, B', D', E' ${ }_{2}, \mathrm{~F}_{1},{ }_{1}, \mathrm{~F}_{2},{ }_{2}, \mathrm{G}^{\prime}, \mathrm{I}_{1}, \mathrm{~J}_{2},{ }_{2}, \mathrm{~K}^{\prime}, \mathrm{O}_{2}, \mathrm{P}^{\prime}, \mathrm{Q}^{\prime}, \mathrm{Y}^{\prime}$, B", G' (EAB); $C_{1}, C_{2}, E, R_{1}, R_{2}, W, X_{1}, X_{2}, C^{\prime}$, L' (EAC); F and V (EAF); J (EAJ); L (EAL); M (EAM); S, U $, \mathrm{U}_{2}, \mathrm{H}^{\prime}, \mathrm{U}^{\prime}, \mathrm{H}^{\prime}, \mathrm{U}^{\prime}$ (EAS); Z (EAZ); $\mathrm{S}^{\prime}$ and $\mathrm{R}$ ' (EAR'). In the antigenic factor detection, the internationally accepted haemolysis test using monospecific reagents was used, the suitability of which was examined by biannual comparison tests organised by the ISAG in $1993-2004$. For the blood group systems EAF and EAR', codominance operates, while for other EA systems a recessive allele segregates. In addition, genes controlling the determination of erythrocyte antigens for multifactor systems are closely linked and are inherited as haplotypic complexes that determine the phenotypic appearance of several antigenic factors or a single antigen. Determination of the antigen complexes (considered here as alleles) in the genotypes of EAA, EAB, EAC, and EAS was carried out using family analysis. Thus, parents of all the 114 individuals were typed in our study to determine their genotypes.

Horizontal polyacrylamide gel electrophoresis was used to separate transferrin (TF) alleles (A, D1, D2, E), as described by Juneja and Gahne (1987). Estonian Native and Estonian Red were typed also for amylase 1 (AMY1), amylase 2 (AMY2) and ceruloplasmin (CP) proteins (unpublished data) using starch gel electrophoresis (Smithies 1955). These proteins were not typed for Estonian Holstein. We used these additional data only in the calculation of the within-population inbreeding coefficient (see results).

\section{Statistical analysis}

In the statistical analysis, the microsatellite and biochemical marker (the 10 blood group systems and transferrin, denoted here and henceforth as EA systems/TF) data sets were examined separately. Locus-wise deviations from Hardy-Weinberg equi- 
Vol. 19(2010): 284-293.

librium (HWE) and pair-wise linkage disequilibrium (LD) between loci within each breed were computed using GENEPOP v.3.4 (Raymond and Rousset 1995a) with the following parameters of the Markov Chain Method: dememorization $=10000$, batches $=1000$ and iterations $=10000$. In the breed-wise LD tests, the frequency of significant results $(p<0.05)$ and the significance of pooled $p$-values of the exact tests using Fisher's method for combining probabilities (Raymond and Rousset 1995b) was reported for microsatellites and EA systems/TF separately. Basic diversity indices, i.e. the unbiased estimates of expected heterozygosity, the number of private alleles and the allelic richness, were calculated and the calculation of the allelic richness was based on 22 (microsatellite data) and 15 individuals (EA systems/TF). The within-population diversity estimates were derived using FSTAT v.2.9.3 (Goudet 2001). This program was also used to compute within-population inbreeding coefficients (f) (Weir and Cockerham 1984).

Genetic differentiation was computed using the variance based method $(\theta)$ of Weir and Cockerham (1984) in FSTAT v. 2.9.3.2 (Goudet 2001). The significance of $\theta$-estimates was determined with 5000 permutations. Moreover, the pattern of population differentiation was described by a factorial correspondence analysis of the individual multilocus scores using GENETIX4.05 (www.genetix. univ-montp2.fr/genetix/genetix.htm). The population clusters derived from the factorial correspondence analysis are identified graphically (Lebart et al. 1984). The first two major components were plotted on a scatter diagram for the three cattle breeds. In addition, Chord genetic distances (Cavalli-Sforza and Edwards 1967) between the breeds were computed using GENETIX4.05.

We conducted an additional genetic differentiation analysis by calculating the allele sharing distances (Bowcock et al. 1994) between 195 individuals of the three Estonian breeds and Danish Jersey and Western Finncattle using the data for 19 microsatellites (INRA035 was excluded, see results). The data for Western Finncattle and Danish Jersey, the breeds which the Estonian Native Cattle Breed Society has used for upgrading of the Estonian Native, were obtained from the study of Tapio et al. (2006). Based on the allele sharing distance matrix, a neighbour-join- ing tree was constructed using SplitsTree4 V4.11.3 software (Huson and Bryant 2006).

\section{Results}

\section{Markers}

All markers were polymorphic across the breeds (Table 1). A total of 209 microsatellite alleles and 122 blood group and transferrin alleles were detected. The number of microsatellite alleles per single locus ranged from 2 (ILSTSO05) to 15 (TGLA053 and TGLA122), and that of EA systems/TF alleles from 2 (EAJ, EAL, EAM, EAF, EAR', and EAZ) to $59(\mathrm{EAB})$. The average expected heterozygosity for the microsatellite loci was 0.70 , and for the biochemical markers 0.41 . EAB and EAC displayed higher levels of expected heterozygosity than any microsatellite marker (Table 1).

In the blood group systems, the genotyping was not totally successful due to discrimination difficulties between probable homozygotes for a dominant allele and heterozygous genotypes for blood groups where a recessive allele was segregating. The EAA and EAS were the most difficult markers to determine an individual's genotype from the antigenic phenotypes, with an overall genotyping success of 76 and 53\%, respectively. In Estonian Native, the genotyping success at dominant marker loci ranged from 55 (EAS) to 90\% (EAL), in Estonian Red from 58 (EAC) to 93\% (EAJ) and in Estonian Holstein from 45 (EAS) to $92 \%$ (EAB). The most complex locus, EAB, was genotyped for 80 and $85 \%$ of Estonian Red and Estonian Native Cattle individuals, respectively.

Nine of a total of $75(12 \%)$ independent tests for Hardy-Weinberg equilibrium (HWE) at the microsatellite loci were rejected at $p<0.05$. When results of the microsatellite loci were pooled across the breeds, INRA035 showed significant ( $p<0.05$, adjusted with a Bonferroni correction) deviation from HWE. This marker showed also a high positive $f$ value (Weir and Cockerham 1984; Table 1). The Mendelian inheritance of microsatellite alleles 
Värv, S. et al. Diversity among the Estonian dairy breeds

Table 1. Microsatellites and Erythrocyte antigen systems/Transferrin protein analysed in the present study, number of alleles $(\mathrm{Na})$ detected, Nei's gene diversity (H) and $f$ estimates calculated according to Weir and Cockerham (1984).

\begin{tabular}{|c|c|c|c|}
\hline Marker & $\mathrm{Na}$ & $\mathrm{H}$ & $f$ \\
\hline$B M 1818$ & 8 & 0.651 & 0.033 \\
\hline BM1824 & 5 & 0.751 & 0.036 \\
\hline$B M 2113$ & 8 & 0.814 & 0.053 \\
\hline CSSM66 & 9 & 0.816 & -0.022 \\
\hline ЕTH003 & 7 & 0.791 & 0.016 \\
\hline ETH010 & 10 & 0.810 & -0.026 \\
\hline ETH152 & 8 & 0.743 & 0.055 \\
\hline ETH225 & 9 & 0.867 & 0.052 \\
\hline HEL001 & 9 & 0.720 & 0.068 \\
\hline HEL005 & 9 & 0.740 & 0.085 \\
\hline HEL009 & 12 & 0.731 & 0.004 \\
\hline HEL013 & 7 & 0.669 & -0.152 \\
\hline ILSTSO05 & 2 & 0.574 & 0.066 \\
\hline ILSTSO06 & 9 & 0.797 & 0.030 \\
\hline INRA005 & 4 & 0.575 & -0.255 \\
\hline INRA023 & 9 & 0.803 & -0.043 \\
\hline INRA032 & 5 & 0.659 & 0.045 \\
\hline INRA035 & 6 & 0.579 & 0.255 \\
\hline INRA037 & 11 & 0.719 & -0.009 \\
\hline INRA063 & 6 & 0.646 & -0.198 \\
\hline SPS115 & 6 & 0.682 & 0.022 \\
\hline$T G L A 053$ & 15 & 0.860 & 0.006 \\
\hline$T G L A 122$ & 15 & 0.803 & 0.005 \\
\hline$T G L A 126$ & 8 & 0.730 & 0.025 \\
\hline TGLA227 & 12 & 0.870 & -0.023 \\
\hline$E A A$ & 3 & 0.328 & -0.178 \\
\hline$E A B$ & 59 & 0.967 & -0.020 \\
\hline$E A C$ & 39 & 0.941 & -0.060 \\
\hline$E A F$ & 2 & 0.322 & -0.162 \\
\hline$E A J$ & 2 & 0.213 & -0.124 \\
\hline$E A L$ & 2 & 0.092 & -0.068 \\
\hline$E A M$ & 2 & 0.036 & -0.021 \\
\hline$E A R^{\prime}$ & 2 & 0.280 & -0.103 \\
\hline$E A S$ & 5 & 0.441 & 0.016 \\
\hline$E A Z$ & 2 & 0.194 & -0.107 \\
\hline$T F$ & 4 & 0.680 & 0.027 \\
\hline
\end{tabular}

was not investigated in this study, but we assume that the deficiency of heterozygotes at INRA035 was due to the presence of non-amplifying null alleles and therefore we excluded INRA035 from further analysis.

In the data set of EA systems/TF, one deviation (transferrin in the Estonian Native) from $\operatorname{HWE}(3 \%$ of the independent tests) was recorded $(p<0.05)$. When the results were pooled and a Bonferroni correction applied to adjust the significance levels, none of the biochemical markers showed deviation from HWE.

\section{Genetic diversity and population structure of the breeds}

The within-population genetic diversity and population structure estimates are given in Table 2. The breeds showed similar levels of within-population diversity in terms of expected heterozygosity and allelic richness on the basis of the microsatellite data. For the EA systems/TF data, however, Estonian Holstein displayed lower within-population diversity than the two other breeds. Our data sets indicated that the number of private alleles was highest in Estonian Red (20 microsatellite alleles over 24 loci and 28 of EAB, EAC and EAS alleles totally).

The within-breed population structure was investigated by computing linkage disequilibrium estimates and inbreeding coefficients for the breeds. For the Estonian Red and Estonian Holstein, the frequency for linkage disequilibrium was less than 5\%, while in Estonian Native this frequency was slightly more than expected by chance (microsatellite data). No linkage disequilibrium was detected in the EA system/TF data and pooled $p$-values from locus-by-locus pair-wise comparison did not indicate any significant deviations from linkage equilibrium proportions. Within-population inbreeding estimates $(f)$ based on microsatellite data did not deviate significantly from zero. However, the negative $f$-estimate obtained from the EA systems/TF analysis suggested the influence of outbreeding in Estonian Native Cattle $(95 \%$ CI for $f$ $[-0.163,-0.086])$. 
Vol. 19(2010): 284-293.

We calculated within-population inbreeding coefficients for Estonian Native and Estonian Red, including three additional codominantly inherited blood protein loci (AMY1, AMY2 and CP) in the data set. Data on these proteins for the Estonian Holstein are not available. We obtained -0.050 and 0.004 for $f$-estimates, with $95 \%$ confidence intervals $[-0.134,0.062]$ and $[-0.054,0.054]$, respectively, suggesting that our estimate for the Estonian Native presented in Table 2 was not robust.

\section{Genetic differentiation}

The overall $\theta$ estimate (Weir and Cockerham 1984) for the microsatellite data was $0.062(95 \% \mathrm{CI}[0.045$, $0.080])$ and for the EA systems/TF data, 0.043 (95\% CI [0.021, 0.067]). All pair-wise $\theta$ comparisons were statistically significantly different from zero $(p<0.05)$ when computed from the microsatellite data (Table 3). For the EA systems/TF data, the respective pair-wise $\theta$ estimates were: 0.051 ( $p<$ $0.05), 0.040(p=0.06)$ and $0.043(p<0.05)$.

In the factorial correspondence analysis of the microsatellite data, the first two principal components (PCs) explained 61.7 and $38.3 \%$ of the total variation, and in the analysis of the EA system/TF data, 53.7 and $46.3 \%$, respectively (Fig. 1a and $1 \mathrm{~b}$ ). The two-dimensional plot constructed from the microsatellite data indicated discrete grouping of the three Estonian cattle breeds with only two Estonian Native and one Estonian Red animals not being assigned to their source population. Based on the EA systems/TF data the demarcation within Estonian Red, Estonian Native and Estonian Holstein clusters was lower than on the microsatellite-based plot, but still discriminated the breeds. However, individuals with intermediate component scores indicated the probable outbred origin of these animals.

Table 2. Within-population diversity values and population structure derived from the microsatellite loci and EA systems/ TF data. Mean expected unbiased heterozygosity $\left(\mathrm{H}_{\text {exp }}\right)$, allelic richness $(\mathrm{R})$, number of private alleles $(\mathrm{A})$, the frequency of significant $(\mathrm{P}<0.05)$ pair-wise linkage disequilibrium test $(\mathrm{LD} \%)$, the pooled exact $\mathrm{P}$-values in the LD-tests $\left(\chi^{2}\right)$ and within-population inbreeding coefficient $(f)$ with $95 \%$ confidence intervals $(95 \% \mathrm{CI})$ are shown.

\begin{tabular}{|c|c|c|c|c|c|c|c|c|c|c|c|c|}
\hline \multirow{2}{*}{ Breed } & \multicolumn{6}{|c|}{ Microsatellite data } & \multicolumn{6}{|c|}{ EA systems/TF data } \\
\hline & $\mathrm{H}_{\text {exp }}$ & $\mathrm{R}$ & A & LD $\%$ & $\chi^{2}$ & $f(95 \% \mathrm{CI})$ & $\mathrm{H}_{\exp }$ & $\mathrm{R}$ & $\mathrm{A}$ & LD $\%$ & $\chi^{2}$ & $f(95 \% \mathrm{CI})$ \\
\hline \multirow{2}{*}{$\begin{array}{l}\text { Est. } \\
\text { Native }\end{array}$} & 0.715 & 6.01 & 16 & 5.4 & $573.1^{\mathrm{NS}}$ & -0.017 & 0.404 & 4.94 & 26 & 0 & $63.9 \mathrm{NS}$ & -0.107 \\
\hline & & & & & & {$[-0.065,0.003]$} & & & & & & {$[-0.163,-0.086]$} \\
\hline \multirow[t]{2}{*}{ Est. Red } & 0.699 & 5.97 & 20 & 4.7 & $511.6^{\mathrm{NS}}$ & 0.026 & 0.405 & 5.14 & 28 & 0 & $37.9 \mathrm{NS}$ & -0.010 \\
\hline & & & & & & {$[-0.022,0.048]$} & & & & & & {$[-0.083,0.031]$} \\
\hline \multirow{2}{*}{$\begin{array}{l}\text { Est. } \\
\text { Holstein }\end{array}$} & 0.694 & 5.87 & 15 & 3.3 & $481.2^{\mathrm{NS}}$ & -0.016 & 0.361 & 4.53 & 16 & 0 & $49.8^{\mathrm{NS}}$ & -0.034 \\
\hline & & & & & & {$[-0.076,0.009]$} & & & & & & {$[-0.119,0.009]$} \\
\hline
\end{tabular}

The significance of pooled P-values of the exact tests in LD analysis using Fisher's method:

${ }^{\mathrm{NS}}$ Not Significant

Table 3. Pair-wise $\theta$ and chord distances between the breeds based on microsatellite (given above the diagonal) and EA systems/TF (below the diagonal)

\begin{tabular}{|c|c|c|c|c|c|c|c|}
\hline \multirow[t]{2}{*}{ Breed } & & \multicolumn{3}{|c|}{ Chord distance } & \multicolumn{3}{|c|}{$\theta$} \\
\hline & & 1 & 2 & 3 & 1 & 2 & 3 \\
\hline Estonian Native & 1 & & 0.058 & 0.095 & & 0.052 & 0.078 \\
\hline Estonian Red & 2 & 0.061 & & 0.075 & 0.051 & & 0.059 \\
\hline Estonian Holstein & 3 & 0.046 & 0.046 & & 0.040 & 0.043 & \\
\hline
\end{tabular}




\section{AGRICULTURAL AND FOOD SCIENCE}

Värv, S. et al. Diversity among the Estonian dairy breeds
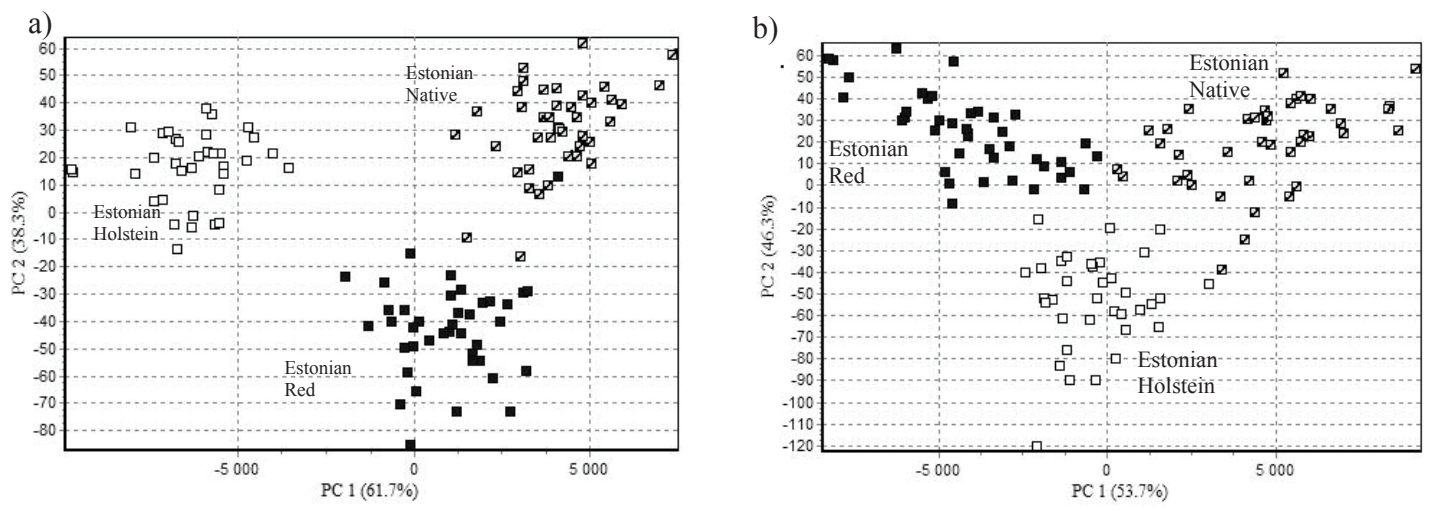

Fig. 1. Plotted representation of three breed clusters as defined by Analysis of Factorial Correspondence: analysis based on a) microsatellites; b) EA systems/TF data.

The analysis of the genetic distances based on the proportion of shared alleles between individuals (Fig. 2) confirmed the close relationship of Estonian Native with Western Finncattle. The grouping of 195 cattle revealed a large mixed group of individuals from the Estonian Native and Western Finncattle and distinct branches of Estonian Red, Estonian Holstein and Danish Jersey cattle confirming the discrete grouping of the Estonian breeds found in the factorial correspondence analysis.

\section{Discussion}

As suggested by our genetic marker analyses, the Estonian Native, Estonian Red and Estonian Holstein breeds are genetically divergent populations among which the gene flow appears to be restricted. The divergence indicates that the present-day gene pool of Estonian dairy cattle is diverse. The $\theta$ estimates (Weir and Cockerham 1984) showed that the Estonian cattle breeds are significantly differentiated and the factorial correspondence analysis (Fig. 1) and allele sharing distances (Fig. 2) confirm the grouping of individuals graphically according to their breed origin. However, as seen in Figure 2 the present Estonian Native cattle population forms an overlapped gene pool with Western Finncattle and it was not possible to determine a special Estonian Native group among the analysed individuals. This finding diminishes the conservation value of the Estonian Native cattle among the North European cattle breeds (Tapio et al. 2006) in terms of genetic uniqueness, but despite this the breed can be considered as an important gene reservoir for agro-biodiversity in the Estonian context.

As shown by the microsatellite data, $6.2 \%$ of the total genetic variation of the Estonian dairy cattle can be explained by differences among the breeds. The level of genetic differentiation among European cattle breeds has been slightly higher, around 10\% (MacHugh et al. 1998; Kantanen et al. 2000), than the present estimate, but estimates have typically been based on a larger set of breeds, from a wider geographic region, than covered in the present study. The current subdivision of the Estonian dairy breeds at the microsatellite loci is comparable to the extent of genetic differentiation among 18 French, Spanish, and Portuguese cattle breeds (a proportion of $7 \%$ among the breeds according to Cañón et al. 2001). Our conclusion re- 
Vol. 19(2010): 284-293.

garding their genetic divergence, is in agreement with the previous study by Tapio et al. (2006), which showed that the North European native, Red and Holstein-Friesian breeds form discrete breed groups.

The EA/TF data indicated a lower level of genetic differentiation among the breeds $(4.3 \%$ of the total genetic variation) than the microsatellites. This could have been due to the lower number of alleles found at the biochemical markers, which may increase the probability that alleles are identical by state but not identical by descent, but partly also due to the lower number of EA system/TF markers analysed in the present study. The standardised genetic differentiation measure $\mathrm{G}_{\text {ST }}$ presented by Hedrick (2005) allows a more appropriate comparison between loci with different mutation rates. We obtained overall $\mathrm{G}_{\mathrm{ST}}{ }_{\mathrm{ST}}$ values of 0.20 for microsatellites $(20 \%$ of the maximum possible) and 0.06 for EA system/transferrin (6\% of the maximum possible). Our data indicate that microsatellites are more valuable markers for diagnostics in breed differentiation and individual assignment analysis of dairy cattle. In addition to microsatellites, the two highly polymorphic blood group systems, EAB and EAC, were found to discriminate cattle breeds more efficiently than other blood groups and even microsatellite loci $\left(\mathrm{G}^{\prime}{ }_{\mathrm{ST}}\right.$ 0.80 at $\mathrm{EAB}$ and 0.54 at EAC). These loci add valuable information for breed differentiation studies including for the private alleles found (e.g. alleles of the EAB Y ${ }_{2} D^{\prime} G^{\prime}, B_{1} G_{2} K^{\prime}, B_{1} G_{2} K^{\prime}{ }^{\prime}{ }^{\prime}{ }_{2}$ and $\mathrm{I}_{2} \mathrm{G}^{\prime} \mathrm{Q}^{\prime}$ in the Estonian Native breed and $\mathrm{BP}^{2}$ ' and $\mathrm{O}_{2} \mathrm{QJ}^{\prime} \mathrm{K}^{\prime} \mathrm{O}$ ' in the Estonian Red breed).

Although recent demographic histories of the Estonian dairy cattle breeds differ considerably, the breeds in general show a similar degree of intrabreed genetic variation (Table 2). The estimates for the Estonian breeds at the microsatellite and at the EA systems/TF markers are comparable with those presented for other European cattle breeds (Kantanen et al. 2000; Li et al. 2007; Tapio et al. 2006). The molecular diversity of the Estonian Holstein breed was measured for the first time in the present study and we found that this effectively selected breed shows similar levels of within-population variation as e.g. Finnish, Russian and French Holstein or Black-and-White cattle populations (Li et
Fig. 2. Neighbour-joining tree showing relationships between cattle of five breeds (Estonian Native, Western Finncattle, Estonian Red, Estonian Holstein, and Danish Jersey) constructed by SplitsTree4 using the allele sharing distances (Bowcock et al. 1994). The individuals of Estonian Native and Western Finncattle located at the same branches on the figure are marked with large circles and small squares, respectively.

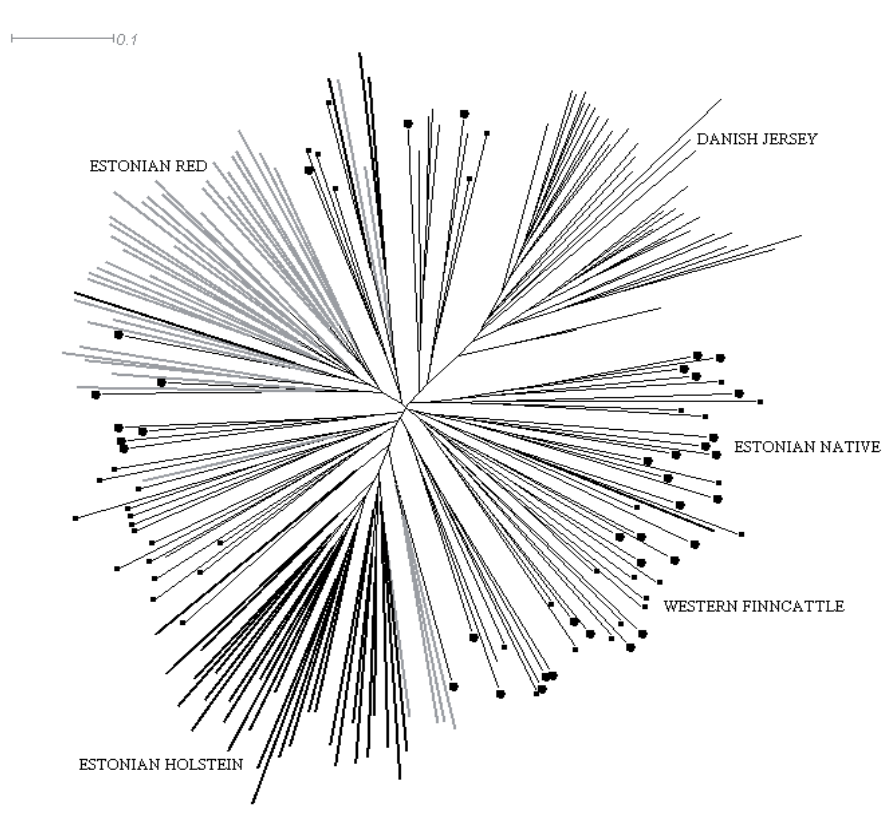


Värv, S. et al. Diversity among the Estonian dairy breeds

al. 2007; Maudet et al. 2002; Tapio et al. 2006; 19 or 20 common microsatellites with our study). The present $f$-estimates calculated from the microsatellite data (Table 2) do not suggest effects of inbreeding or outbreeding in the Estonian breeds. However, the biochemical marker data point towards outbreeding in Estonian Native Cattle. When additional protein loci were included in the analysis, the outbreeding was less apparent. We speculate that the test statistics did not reveal an outbreeding effect in the Estonian breeds (although they have been influenced by other breeds) because genetically closely related breeds have been used for crossing.

The present microsatellite and biochemical marker data gave inconsistent results on breed relationships (Table 3; Fig. 1). The Estonian breeds did not show a fragmented population structure (Table 2), which could have been one source of discrepancy, as reported by Tapio et al. (2003). The microsatellite data may provide more reliable results on between-breed diversity compared with documented breed histories (Kantanen et al. 2000; Rendo et al. 2004; Wiener et al. 2004; Tapio et al. 2006). As pointed out by Bowcock et al. (1994), markers with a large number of alleles typically show less biased estimates than those based on low-polymorphic markers. On the other hand, we typed more microsatellite markers than biochemical markers, which increases the reliability of analysis (Takezaki and Nei 1996).

Our genetic marker analysis indicated that the Estonian dairy cattle gene pool is variable. The breeds have diverged as reflected also by the relatively high number of private alleles detected in each breed. However, the future trends may threaten this diversity in the Estonian dairy cattle gene pool. For example, the old type of Estonian Red studied here is rapidly disappearing due to crossbreeding with Red Holstein and with other European red cattle. We conclude that the DNA samples and genotyping data collected in the present study will be of value in future studies examining, for example, temporal changes in the genetic diversity of Estonian dairy cattle breeds.
Acknowledgements. This work was supported by the Nordic Council of Ministers and the Nordic Genetic Resource Center (NordGen), targeted financing of research project SF1080022s07 and applied research of the Ministry of Agriculture of Estonia.

\section{References}

Arranz, J. J., Bayón, Y. and San Primitivo, F. 1996. Comparison of protein markers and microsatellites in differentiation of cattle populations. Animal Genetics 27: 415-419.

Barker, J.S.F., Moore, S.S., Hetzel, D.J. S., Evans, D., Tan, S.G. and Byrne, K. 1997. Genetic diversity of Asian water buffalo (Bubalus bubalis): microsatellite variation and a comparison with protein-coding loci. Animal $\mathrm{Ge}$ netics 28: 103-115.

Blott, S.C., Williams J.L. and Haley, C.S. 1998. Genetic relationship among European cattle breeds. Animal Genetics 29: 273-282.

Bowcock, A., M., Ruiz-Linares, A., Tomfohrde, J., Minch, E., Kidd, J.R. and Cavalli-Sforza, L.L. 1994. High resolution of human evolutionary trees with polymorphic microsatellites. Nature 368: 455-457.

Cañón, J., Alexandrino, P., Bessa, I., Carleos, C., Carretero, J., Dunner, S., Ferran, N., Garcia, D., Jordana, J., Laloè, D., Pereira, A., Sanchez, A. and Moazami-Goudarzi, K. 2001. Genetic diversity measures of local European beef cattle breeds for conservation purposes. Genetics Selection Evolution 33: 311-332.

Cavalli-Sforza, L.L. and Edwards, A.W.F. 1967. Phylogenetic analysis: models and estimation procedures. American Journal of Human Genetics 19: 233-257.

Goudet, J. 2001. FSTAT, a program to estimate and test gene diversities and fixation indices (version 2.9.3). Available from http://www.unil.ch/izea/softwares/fstat. html.

Hedrick, P.W. 2005. A standardized genetic differentiation measure. Evolution 59: 1633-1638.

Huson, D.H. and Bryant D. 2006. Application of Phylogenetic Networks in Evolutionary Studies. Molecular Biology and Evolution 23: 254-267. Software available from www.splitstree.org.

Ibeagha-Awemu, E. M., Jäger, S. and Erchardt, G. 2004. Polymorphisms in blood proteins of Bos indicus and Bos taurus cattle breeds of Cameroon and Nigeria, and description of new albumin variants. Biochemical Genetics 42: 181-197.

Juneja, R.K. and Gahne, B. 1987. Simultaneous phenotyping of pig plasma a-proteaseinhibitors (PI1, PO1A, $\mathrm{PO} 1 \mathrm{~B}, \mathrm{PI} 2)$ and four other proteins (PO2, TF, CP, HPX) by a simple method of $2 \mathrm{D}$ horizontal electrophoresis. Animal Genetics 18: 197-211.

Kantanen, J., Olsaker, I., Adalsteinsson, S., Sandberg, K., Eythorsdottir, E., Pirhonen, K. and Holm, L.-E. 1999. Temporal changes in genetic variation of Northern European cattle breeds. Animal Genetics 30: 16-27. 


\section{AGRICULTURAL AND FOOD SCIENCE}

Vol. 19(2010): 284-293.

Kantanen, J., Olsaker, I., Holm, L.-E., Lien, S., Vilkki, J., Brusgaard, K., Eythorsdottir, E., Danell, B. and Adalsteisson, S. 2000. Genetic diversity and population structure of 20 North European cattle breeds. Journal of Heredity 91: 446-457.

Lebart, L., Morineau, A. and Warwick, K.M. 1984. Multivariate Descriptive Statistical analysis: Correspondence Analysis and Related Techniques for Large Matrices. John Wiley ansd Sons, New York.

Li, M.H., Tapio, I., Vilkki, J., Ivanova, Z., Kiselyova, T., Marzanov, N., Ćinkulov, M., Stonajović, S., Ammosov, I., Popov, R. and Kantanen, J. 2007. The genetic structure of cattle population (Bos taurus) in northern Eurasia and the neighbouring Near Eastern regions: implications for breeding strategies and conservation. Molecular Ecology 16: 3839-3853.

Luís, C., Juras, R., Oom, M.M. and Cothran, E.G. 2007. Genetic diversity and relationship of Portugese and other horse breeds based on protein and microsatellite loci variation. Animal Genetics 38: 20-27.

MacHugh, D.E., Loftus, R.T., Cunningham, P. and Bradley, D.G. 1998. Genetic structure of seven European cattle breeds assessed using 20 microsatellite markers. Animal Genetics 29: 333-340.

Mao, Y., Chang, H., Yang, Z., Zhang, L., Xu, M., Sun, W., Chang, G and Song, G. 2007. Genetic structure and differentiation of three Chinese indigenous cattle populations. Biochemical Genetics 45: 195-209.

Maudet, C., Luikart, G., and Taberlet, P. 2002. Genetic diversity and assignment tests among seven French cattle breeds based on microsatellite DNA analysis. Journal of Animal Science. 80: 942-950.

Moazami-Goudarzi, K., Laloë, D., Furet, J.P. and Grosclaude, F. 1997. Analysis of genetic relationships be- tween 10 cattle breeds with 17 microsatellites. Animal Genetics 28: 338-345.

Raymond, M. and Rousset, F. 1995a. Genepop (Version 3.1d, updated version of Genepop v. 1.2): population genetics software for exact tests and ecumenicism. Journal of Heredity 86: 248-249.

Raymond, M. and Rousset, F. 1995b. An exact test for population differentiation. Evoution 49: 1280-1283.

Rendo, F., Iriondo, M., Jugo, B.M., Aguirre, A., Mazón, L.I., Vicario, A., Gómez, M. and Estonba, A. 2004. Analysis of the genetic structure of endangered bovine breeds from the western Pyrenees using DNA microsatellite markers. Biochemical Genetics 42: 99-108.

Smithies, O. 1955. Zone electrophoresis in starch gels: Group variation in the serum proteins of normal human adults. Biochemical Journal 61: 629.

Takezaki, N. and Nei, M. 1996. Genetic distances and reconstruction of phylogenetic trees from microsatellite DNA. Genetics 144: 389-399.

Tapio, I., Värv, S., Bennewitz, J., Maleviciute, J., Fimland, E., Grislis, Z., Meuwissen, T.H.E., Miceikiene, I., Olsaker, I., Viinalass, H., Vilkki, J. and Kantanen, J. 2006. Prioritization for conservation of Northern European cattle breeds based on analysis of microsatellite data. Conservation Biology 20: 1768-1779.

Tapio, M., Miceikiene, I., Vilkki, J. and Kantanen, J. 2003. Comparison of microsatellite and blood protein diversity in sheep: inconsistencies in fragmented breeds. Molecular Ecology 12: 2045-2056.

Weir, B.C. and Cockerham, C.C. 1984. Estimating F-statistics for the analysis of population structure. Evolution 38: 1358-1370.

Wiener, P., Burton, D. and Williams, J.L. 2004. Breed relationships and definition in British cattle: a genetic analysis. Heredity 93: 597-602. 